\title{
Hematoma escrotal como primera manifestación de hematoma retroperitoneal tras litotricia extracorpórea
}

\author{
Vega Vega A, Crespo Toral F, Rodríguez Lamelas JM. \\ Servicio de Urología, Obra Hospitalaria Nuestra Señora de Regla, León.
}

Actas Urol Esp. 2008;32(3):360-362

\section{RESUMEN}

HEMATOMA ESCROTAL COMO PRIMERA MANIFESTACIÓN DE HEMATOMA RETROPERITONEAL TRAS LITOTRICIA EXTRACORPÓREA

Describimos el caso de un paciente que a las 15 horas del tratamiento y fragmentación de una litiasis en el uréter proximal mediante litotricia extracorpórea presenta un hematoma escrotal indoloro como única manifestación de hematoma subcapsular.

Palabras Clave: Hematoma retroperitoneal. Litotricia. Hematoma escrotal.

\section{ABSTRACT}

SCROTAL HAEMATOMA AS A SIGN OF RENAL HEMATOMA AFTER ESWL

We described the case of a patient who presented a large scrotal black discoloration 15 hours after successful extracorporeal lithotripsy of a proximal ureteral calculus. The patient did not present any other clinical symptoms as a sign of subcapsular haematoma.

Keywords: Retroperitoneal haematoma. Lithotripsy. Scrotal haematoma.

$\mathrm{L}^{\mathrm{a}}$ a litotricia extracorpórea por ondas de choque es el tratamiento de primera elección en más de un 90\% de las litiasis de origen urinario, debido principalmente al alto porcentaje de eficacia en la fragmentación con su posterior eliminación y a ser una técnica en la que el número de complicaciones es mínimo ${ }^{1}$. Se han descrito como complicaciones de la litotricia extracorpórea el cólico renal al paso de los fragmentos de la litiasis por el uréter, obstrucción del uréter, calle litiásica, infección urinaria, bacteriemia, contusión renal, hematoma perirrenal/retroperitoneal, ileo paralítico, contusión de la pared abdominal y arritmias cardíacas ${ }^{1}$. La complicación más grave es el hematoma renal, el cual se produce en un $0,5-1 \%$ de los casos, siendo normalmente autolimitado y no precisando medidas terapeúticas agresivas. El tratamiento habitual es el reposo y reposición sanguínea si precisa ${ }^{2}$. Esta complicación se asocia a la presencia de hipertensión arterial o alteraciones de la coagulación en el paciente, también se relaciona con el número de ondas, así como al empleo de alta energía en las mismas durante el tratamiento $^{3}$. Su diagnóstico suele ser clínico, con presentación del dolor constante en el flanco que cede mal al tratamiento, no suele ser un dolor tan fuerte como en los cólicos pero si muy persistente e invalidante y sin justificación ${ }^{4}$. Su confirmación es radiológica, mediante ecografía y/o TAC.

Exponemos un paciente en el que el diagnóstico del hematoma renal tras litotricia fue la aparición al día siguiente de un hematoma escrotal asintomático.

\section{CASO CLINICO}

Paciente varón de 69 años de edad, con historia de episodios recurrentes durante una semana de dolor en el flanco izquierdo con irradiación hacia genitales, sin antecedentes personales de interés, ni historia de hipertensión arterial previa ni alteraciones de la coagulación. A la exploración física no se encontró ninguna anomalía salvo dolor a la palpación profunda en el flanco abdominal izquierdo. En la Urografía Intravenosa se observa una litiasis de 7 x $6 \mathrm{~mm}$ en la unión pielo-ureteral (Fig. 1) que produce un ligero retraso excretor con una ureterohi- 


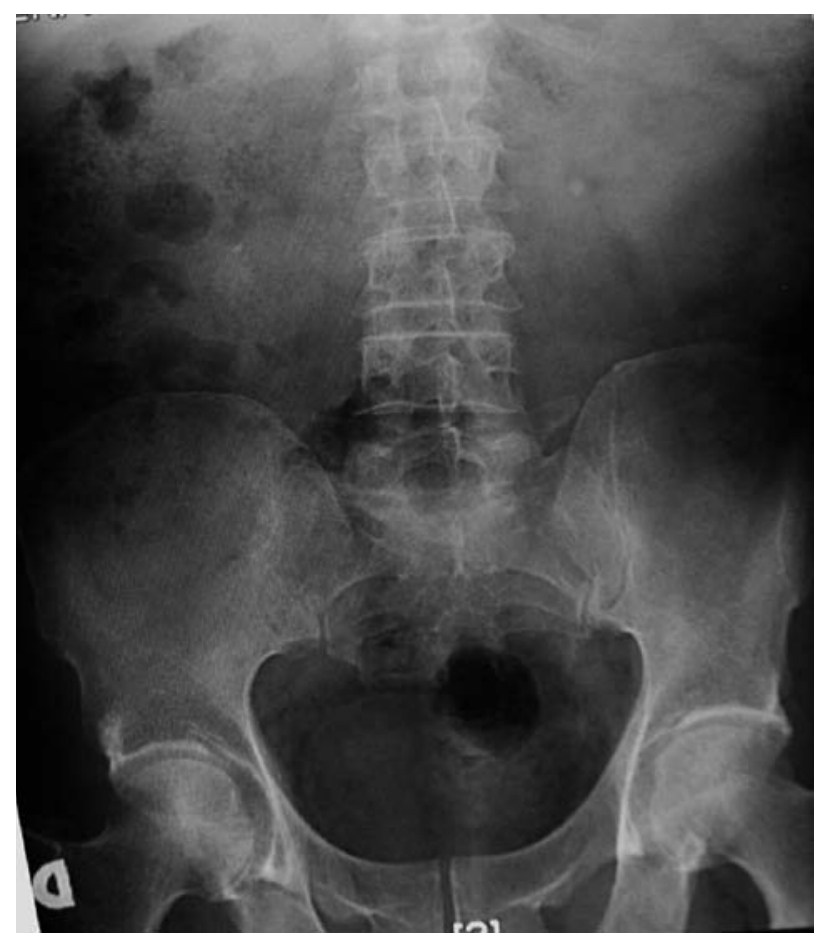

FIGURA 1. Litiasis en unión pielo-ureteral izquierda de $6 x$ $7 \mathrm{~mm}$ previo a litotricia.

dronefrosis muy leve. Al paciente se le trató de forma ambulatoria, primero se corrigió el dolor del episodio agudo, seguido de litotricia extracorpórea in situ con el litotritor Siemens Modularis. Se le aplicaron 3.500 ondas de choque con una intensidad media de 1,4 mjul/mm2 con el paciente colocado en posición supina. Se aplicó una sedación de 1 mg de midazolan y $1 \mathrm{mg}$ de alfentanilo, la tolerancia a la litotricia fue buena. Durante el proceso se observó la fragmentación completa de la litiasis en el seguimiento y localización de la litiasis con rayos $X$. Una vez finalizado el tratamiento el paciente se fue a su domicilio.

A las 15 horas del tratamiento, el paciente acude a urgencias de este Centro por la presencia de un hematoma escrotal indoloro. El examen físico revela una marcada equímosis en el escroto, pene y suprapúbico (Fig. 2). El hematocrito del paciente presenta unos valores similares a los del día anterior, $42 \%$. El estudio por Ecografía y TAC abdominal revela un hematoma subcapsular, perirenal (Fig. 3), descendiendo retroperitonealmente hasta el escroto. El paciente estuvo estable hemodinámicamente durante todo el proceso, no precisando transfusión. Se le ingresó en el Centro y se le trató con reposo en cama y antibióticos profilácticos: ciprofoxacino 500, 1/12

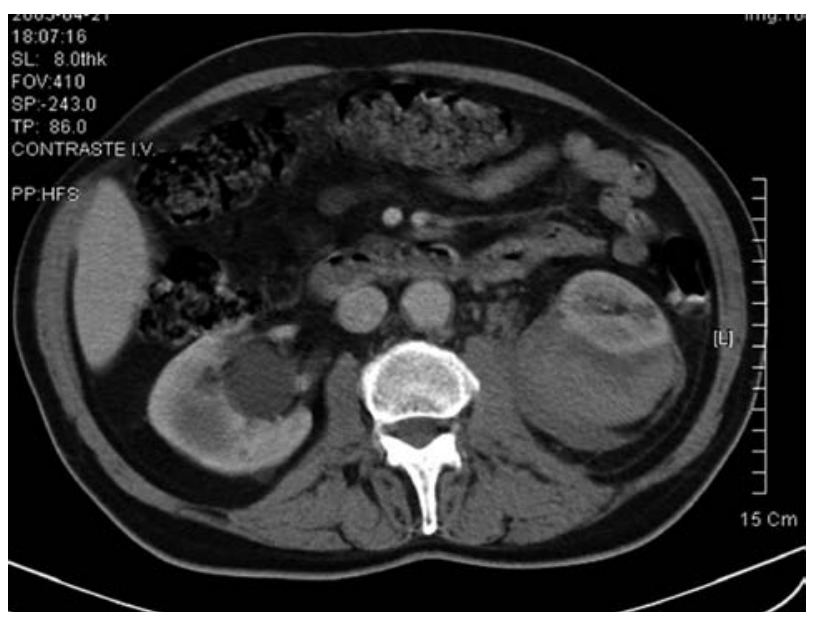

FIGURA 2. Hematoma perirrenal en lado izquierdo tras litotricia.

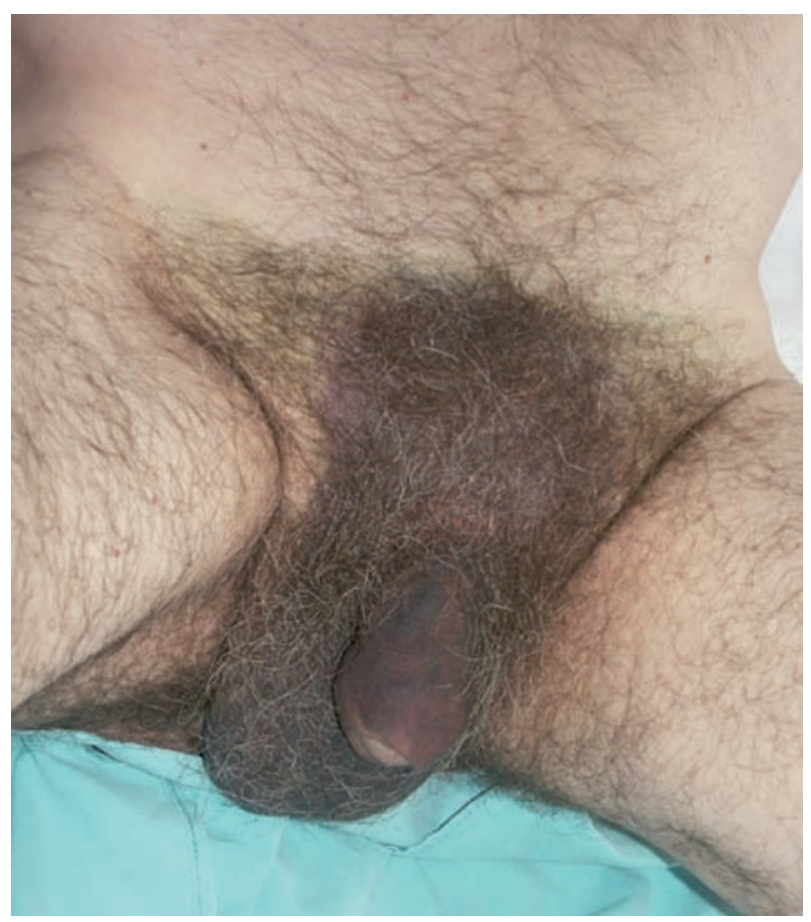

FIGURA 3. Hematoma escrotal tras litotricia.

horas durante 1 semana. Evolucionó bien, dándosele el alta a los 5 días. En la revisión a los 3 meses se observó la reabsorción completa del hematoma.

\section{DISCUSIÓN}

La litotricia extracorpórea es el método de elección de tratamiento de la mayoría de las litiasis del aparato urinario, con un escaso porcentaje de complicaciones. El hematoma renal tras litotricia extracorpórea es una complicación infrecuente, aunque tal vez la más grave, los principales factores de riesgo son la 
hipertensión y alteraciones de la coagulación primarios o secundarios al tratamiento antiagregante. También influye el número de ondas de choque y la energía de estas $^{3}$. Se manifiesta principalmente como dolor en el flanco y el tratamiento de elección suele ser conservador.

En la revisión bibliográfica sólo hemos encontrado 3 casos de hematoma escrotal secundarios a litotricia extracorpórea ${ }^{5-7}$. Las principales diferencias con este caso son que en uno de ellos el hematoma fue secundario al tratamiento de una litiasis localizada en el uréter distal, con un efecto directo de las ondas de choque en el escroto ${ }^{7}$. En los otros 2 casos la presencia de hematoma escrotal se debía a la existencia de un gran hematoma retroperitoneal, con un abdomen a tensión, que era evidente a la exploración física $^{5,6}$. En 2 de los 3 casos el hematoma se acompañó de dolor intenso que precisó analgesia. En nuestro caso el paciente no tuvo dolores y tampoco se observó la presencia de masa ni defensa abdominal y tampoco fue necesario transfundirle. El hematoma presentaba una localización principalmente subcapsular, con un aumento de densidad leve y definido que descendía por retroperitoneo, próximo al psoas hasta el escroto. El mecanismo que proponemos de emigración del hematoma desde el espacio perirenal hasta el pubis y escroto es la migración acompañando la arteria y vena espermática hasta el anillo inguinal y posteriormente al escroto. Aunque sumamente extraño, la aparición de un hematoma escrotal en un paciente en tratamiento con litotricia nos ha de hacer sospechar de la existencia de un hematoma renal.

\section{REFERENCIAS}

1. Coptcoat MJ, Webb DR Kellet MJ, Fletcher MS, McNicholas TA, Dickinson IK, Whitefield HN, Wickman JEA. The complications of extracorporeal shockwave lithotripsy. Management and prevention. Br J Urol 1986; 55;578-580.

2. Knapp PM, Kilb TB, Lingeman J, Newman DM, Mertz JH, Masbough PG, Steele RE. extracorporeal shock wave lithotripsyinduced perirenal hematomas. J Urol 1988; 139:700-705.

3. Newman LH, Saltzman B. Identifying risk factors in development of clinically significant post-shock wave lithotripsy subcapsular hematomas. Urology 1991; 38: 35-39.

4. Gallego Sanchez JA, Ibarlucea Gonzáez G, Gamarra Quintanilla M, Gusisasola J, Bernuy Malfaz C. Hematomas renales tras litotricia extracorpórea con el litotritor "lithostar multiline de Siemens", Actas Urol Esp 2000; 24:19-22.

5. Blacklock ARE. Painless scrotal bruising following extracorporeal shock wave lithotripsy for renal calculus. Br J Urol. 1994;74; 675-676.

6. Biri H, Sinik Z, Alkibay T, Karaoglan Ü, Bozkirli J. Scrotal bruising as a sign of retroperitoneal haematoma following extracorporeal shock wave lithotripsy. Int Urol and Nephrol 1997; 29:287-290.

7. Kaye MC, Streem SB, Yost A. Scrotal hematoma resulting from extracorporeal shock wave lithotripsy for a distal ureteral calculus. J Urol. 1993; 150:481-482.

Correspondencia autor: Dr. A. Vega Vega

Servicio de Urología. Obra Hospitalaria Nuestra Señora de Regla

Cardenal Landázuri, 2 - 24003 León

Tel.: 987236900

E-mail autor: debgarcia100@hotmail.com

Información artículo: Nota Clínica

Trabajo recibido: septiembre 2006

Trabajo aceptado: octubre 2006 